\title{
Plasma advanced glycation end-products and skin autofluorescence are increased in COPD
}

\author{
Poornima Gopal', Niki L. Reynaert ${ }^{1}$, Jean L.J.M. Scheijen², Lean Engelen², \\ Casper G. Schalkwijk², Frits M.E. Franssen ${ }^{3}$, Emiel F.M. Wouters ${ }^{1,3}$ and \\ Erica P.A. Rutten ${ }^{3}$
}

Affiliations: ${ }^{1}$ Dept of Respiratory Medicine, Maastricht University Medical Center+ (MUMC), Maastricht, ${ }^{2}$ Dept of Internal Medicine, MUMC, Maastricht, and ${ }^{3}$ Centre of Expertise for Chronic Organ Failure (CIRO), Horn, The Netherlands.

Correspondence: E.P.A. Rutten, Program Development Centre, Centre of Expertise for Chronic Organ Failure (CIRO), PO Box 4080, Hornerheide, The Netherlands. E-mail: ericaruttenlaciro-horn.nl

ABSTRACT Chronic obstructive pulmonary disease (COPD) is associated with systemic inflammation and oxidative stress. These conditions may lead to the formation of advanced glycation end-products (AGEs).

In this study we investigated in 88 COPD patients and 55 control subjects ( $80 \%$ ex-smokers) the association of the plasma protein-bound AGEs $\mathrm{N}^{\varepsilon}$-(carboxymethyl)lysine (CML), pentosidine, $\mathrm{N}^{\varepsilon}$-(carboxyethyl)lysine (CEL), and AGE accumulation in skin by skin autofluorescence (AFR), with lung function.

Mean $\pm \mathrm{SD}$ plasma CML was decreased (COPD $61.6 \pm 15.6 \mathrm{nmol} \cdot \mathrm{mmol}^{-1}$ lysine, never-smokers $80.7 \pm 19.8 \mathrm{nmol} \cdot \mathrm{mmol}^{-1}$ lysine and ex-smokers $82.9 \pm 19.3 \mathrm{nmol} \cdot \mathrm{mmol}^{-1}$ lysine) and CEL (COPD $39.1 \pm 10.9 \mathrm{nmol} \cdot \mathrm{mmol}^{-1}$ lysine, never-smokers $30.4 \pm 5.0 \mathrm{nmol} \cdot \mathrm{mmol}^{-1}$ lysine and ex-smokers $27.7 \pm 6.4 \mathrm{nmol} \cdot \mathrm{mmol}^{-1}$ lysine) and AFR (COPD $3.33 \pm 0.67$ arbitrary units (AU), never-smokers $2.24 \pm 0.45 \mathrm{AU}$ and ex-smokers $2.31 \pm 0.47 \mathrm{AU})$ were increased in COPD patients compared to controls. Disease state was inversely associated with CML, and linearly associated with CEL and AFR. Performing regression analyses in the total group, CEL and AFR showed a negative association and CML a positive association with lung function, even after correction for potential confounders.

In conclusion, CEL and AFR were negatively and CML was positively associated with disease state. In the total group only the AGEs showed an association with forced expiratory volume in $1 \mathrm{~s}$. Our data suggest that AGEs are involved in the pathophysiology of COPD, although their exact role remains to be determined.

@ERSpublications

Advanced glycation end-products are involved in the pathophysiology of COPD, but their exact role remains unknown http://ow.ly/r2wBR

This article has supplementary material available from www.erj.ersjournals.com

Received: Aug 282012 | Accepted after revision: March 062013 | First published online: May 032013

Support statement: This study was supported by Netherlands Astma Fonds (AF2009, project no: 3.2.09.049). The study was performed within the framework of the Dutch Top Institute 317 Pharma project T1-201. Maastricht University Medical Center, University Medical Center Groningen, University Medical Center Utrecht, GlaxoSmithKline, AstraZeneca, Nycomed and Danone Research were partners of this project. The partners had no role in the data interpretation or writing of the manuscript.

Conflict of interest: None declared.

Copyright @ERS 2014 


\section{Introduction}

Chronic obstructive pulmonary disease (COPD) is a major and increasing global problem predominantly associated with lung pathology. It is a chronic inflammatory disease of the lower airways, caused by longterm inhalation of noxious gasses, especially cigarette smoke. The pathological characteristics of COPD are destruction of lung parenchyma or emphysema, inflammation of the central airways and an increase in the number of mucus producing cells. The airflow limitation, measured by reduced forced expiratory volume in $1 \mathrm{~s}$ (FEV1), is usually progressive. Apart from pulmonary pathology, COPD is characterised by systemic inflammation and oxidative stress [1], the origin of which is not yet known. Chronic inflammation and local/systemic oxidative stress may lead to the increased formation and accumulation of systemic levels of advanced glycation end-products (AGEs).

AGEs are a class of compounds formed from the nonenzymatic glycation and oxidation of proteins and lipids. Production of these molecules through the classical pathway takes weeks to months and involves many reversible intermediates that finally lead to the formation of irreversible AGEs [2]. An alternative pathway is induced by increased oxidative, inflammatory and glycaemic stress and will result in the formation of AGEs by reactive dicarbonyl compounds within hours [3]. The best characterised AGEs to date are $\mathrm{N}^{\varepsilon}$-(carboxymethyl)lysine $(\mathrm{CML})$, pentosidine and $\mathrm{N}^{\varepsilon}$-(carboxyethyl)lysine (CEL). AGEs are ligands of the receptor for AGEs. Similar to other ligands of this receptor, including high-mobility group box-1 and serum amyloid A, binding leads to the activation of the transcription factor nuclear factor- $\kappa \mathrm{B}$, resulting in the production of inflammatory cytokines $[4,5]$.

Some AGEs, such as pentosidine, are characterised by their yellow-brown fluorescent colour and their ability to form stable inter- and intramolecular cross-links [6] on long-lived proteins such as skin collagen and lens proteins [7-10]. Because of these special fluorescent characteristics their accumulation on skin collagen can be estimated noninvasively using a skin autofluorescence (AFR) reader, also called an AGE reader [11]. Recent evidence has shown that AFR increases with age and is increased in patients with diabetes [12-14]. In COPD, it has been shown that CML is increased in epithelial lining fluid from peripheral airways as compared to healthy ex- and current smokers [15]. Because systemic oxidative stress and persistent systemic inflammation are present in COPD, we hypothesise that AGEs, in plasma and skin, are increased in COPD. This study was therefore designed to investigate primarily the plasma concentrations of protein-bound CML, CEL and pentosidine, as well as AFR, in COPD patients compared to healthy controls and to examine their relationship to disease state and lung function. Secondly, the relationship of plasma AGEs with AFR was examined.

\section{Methods \\ Study population}

The study population included 114 clinically stable, moderate-to-severe COPD patients referred for pulmonary rehabilitation, who were recruited from the Centre of Expertise for Chronic Organ Failure (CIRO, Horn, the Netherlands) and 61 healthy (ex-/never-)smoking controls. Clinical history of COPD and the degree of disease severity were assessed according to the published American Thoracic Society, Global Initiative for Chronic Obstructive Lung Disease (GOLD) guidelines [16]: post-bronchodilator FEV $1<80 \%$ predicted and $\mathrm{FEV} 1 /$ forced vital capacity $(\mathrm{FVC})<70 \%$. Exclusion criteria were a history of tumour, diabetes and exacerbation of COPD within $<4$ weeks before blood draw and skin reading. Control subjects were judged healthy by a standardised health questionnaire. This study was approved by the local medical ethical committee.

The number of pack-years ((number of packs of cigarettes smoked per day/20) $\times$ number of years smoked) and smoking status (never-/current/ex-smoker) were recorded. People with 0 pack-years were considered as never-smokers, $>10$ pack-years were considered smokers and those who stopped smoking $\geqslant 1$ year prior to recruitment were considered ex-smokers.

Lung function was determined using spirometry, and FEV1 and FVC were calculated from the flow-volume curve. Height and weight were measured in every participant and body mass index (BMI) was calculated $\left(\mathrm{kg} \cdot \mathrm{m}^{-2}\right)$. Self-reported medication history and associated comorbidities of the patients and controls were recorded. $63.7 \%$ of patients were on long- and/or short-acting muscarinic antagonists, $52.9 \%$ on combination therapy of long-acting $\beta_{2}$-agonists (LABA) and inhaled corticosteroids, $39.2 \%$ on LABA, $22.5 \%$ on short-acting $\beta_{2}$-agonists, $16.7 \%$ were on low-dose oral steroids, $10.8 \%$ on inhaled steroids, $8.8 \%$ on $\mathrm{N}$-acetylcysteine and $20.6 \%$ were on statins.

\section{Blood collection and determination of plasma markers}

Blood was collected in an evacuated tube containing EDTA (Sherwood Medical, St Louis, MO, USA) and immediately centrifuged at $1000 \times g$ for $10 \mathrm{~min}$ at $4^{\circ} \mathrm{C}$. The plasma samples were subsequently stored at $-80^{\circ} \mathrm{C}$ until analysis. Plasma protein-bound CML and CEL were measured by liquid chromatography 
TABLE 1 General characteristics of chronic obstructive pulmonary disease (COPD) patients and controls

\begin{tabular}{|c|c|c|c|}
\hline & Controls & Stable COPD & p-value \\
\hline Subjects $\mathrm{n}$ & 55 & 88 & \\
\hline Age years & $60 \pm 6$ & $63 \pm 8$ & 0.016 \\
\hline Male & $26(47.3)$ & $46(52.3)$ & 0.937 \\
\hline $\begin{array}{l}\text { Smoking pack-years" } \\
\text { Smoking status }{ }^{\mathbb{T}} \mathrm{n}(\%)\end{array}$ & $12.2 \pm 13.3$ & $35.0 \pm 16.1$ & $<0.001$ \\
\hline Ex-smoker & $43(78.2)$ & $64(72.7)$ & \\
\hline Never-smoker & $11(20)$ & & \\
\hline Current smoker & & 18 (20.5) & \\
\hline BMI $\mathbf{k g} \cdot \mathrm{m}^{-2}$ & $27.5 \pm 3.9$ & $26.1 \pm 5.2$ & 0.069 \\
\hline $\mathrm{FFMI} \mathrm{kg} \cdot \mathrm{m}^{-2}$ & $18.2 \pm 2.4$ & $16.94 \pm 2.8$ & 0.004 \\
\hline FEV $1 \%$ pred & $118(109.0-128.0)$ & $45.50(32.25-61.0)$ & $<0.001$ \\
\hline 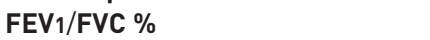 & $78.97(75.2-82.43)$ & $51.88(38.25-63.25)$ & $<0.001$ \\
\hline DLco \% pred & & $51.46(42.4-73.19)$ & \\
\hline BODE score & & $3.50(2.0-8.0)$ & \\
\hline Charlson comorbidity index & & $1.0(0.00-3.0)$ & \\
\hline Triglycerides $\mathrm{mg} \cdot \mathrm{dL}^{-1}$ & $4.5(4.3-5.8)$ & $4.69(4.5-5.7)$ & 0.748 \\
\hline $\mathrm{HDL}$ cholesterol $\mathrm{mg} \cdot \mathrm{dL}^{-1}$ & $68.3 \pm 19$ & $75 \pm 27$ & 0.096 \\
\hline Glucose $\mathrm{mg} \cdot \mathrm{dL}^{-1}$ & $102.5 \pm 11.7$ & $102 \pm 69$ & 0.938 \\
\hline Creatinine $\mu \mathrm{mol} \cdot \mathrm{L}^{-1}$ & $82.3 \pm 14.0$ & $90.2 \pm 24.8$ & 0.049 \\
\hline CRP $\mathrm{mg} \cdot \mathrm{L}^{-1}$ & $0.64(0.33-1.59)$ & $3.4(1.7-8.5)$ & $<0.001$ \\
\hline GFR $\mathrm{mL} \cdot \mathrm{min}^{-1}$ & $77.1 \pm 14.2$ & $73.7 \pm 20.8$ & 0.280 \\
\hline Protein carbonylation $\mathrm{nmol} \cdot \mathrm{mL}^{-1}$ & $2.73(2.7-4.1)$ & $2.8(2.7-4.0)$ & 0.254 \\
\hline
\end{tabular}

Data are presented as mean \pm SD, $\mathrm{n}(\%)$ or median (interquartile range), unless otherwise stated. BMI: body mass index; FFMI: fat-free mass index; FEV1: forced expiratory volume in $1 \mathrm{~s}$; \% pred: \% predicted; FVC: forced vital capacity; DLCO: diffusing capacity of the lung for carbon monoxide; BODE: BMI, airflow obstruction, dyspnoea, exercise capacity; HDL: high density lipoprotein; CRP: C-reactive protein; GFR: glomerular filtration rate. " : data missing for 34 patients, but smoking stop date is available for this group; ": data for six patients and one control subject were missing because of missing information on pack-years smoked or smoking stop date.

tandem mass spectrometry [17] and pentosidine was measured by high-performance liquid chromatography with fluorescence detection [18] and expressed per lysine concentrations.

Oxidative damage of plasma protein was assessed by measuring plasma protein carbonyls by a spectrophotometric assay. In brief, plasma protein carbonyls were derivatised with 2,4-dinitro-phenyl hydrazine to form protein hydrazine, which can be measured at 360-385 $\mathrm{nm}$ [19].

Plasma levels of high-density lipoproteins (HDL), triglycerides, glucose, C-reactive protein (CRP) and creatinine were measured in an auto-analyzer (ABX Pentra 400; HORIBA, Montpellier, France). Glomerular filtration rate (GFR) was calculated using the Cockcroft-Gault formula [20].

\section{Skin AFR}

AFR was determined by an AGE reader (version 2.1; DiagnOptics Technologies BV, Groningen, the Netherlands). AFR was measured on the volar side of the lower part of the dominant arm in every participant, at room temperature and in a dark environment. Care was taken to perform the measurement in an area without any scar, visible vessels, lichenification or other skin abnormalities. In brief, the excitation source was a 4-W UVA-emitting lamp that emits light with a wavelength of 300-420 nm (peak $360 \mathrm{~nm}$ ). Light reflected and emitted in the 300-600 nm range from the skin is measured by the inbuilt spectrometer using a UV glass fibre. In addition, dark and white reference readings were performed before every measurement to correct for dark-current background light and to calculate reflectance, respectively. To correct for difference in light absorption, AFR was calculated as ratio of excitation light (300-420 nm) to emitted light (420-600 nm) and expressed as arbitrary units (AU) [21, 22]. Only AFR with a reflectance $>0.1$ was considered for further investigation.

\section{Statistical methods}

SPSS (version 17, IBM, Chicago, IL, USA) was used for the data analysis. Variables with skewed distribution such as CRP, FEV1 \% pred, pentosidine and triglycerides were log-transformed before further analysis. 

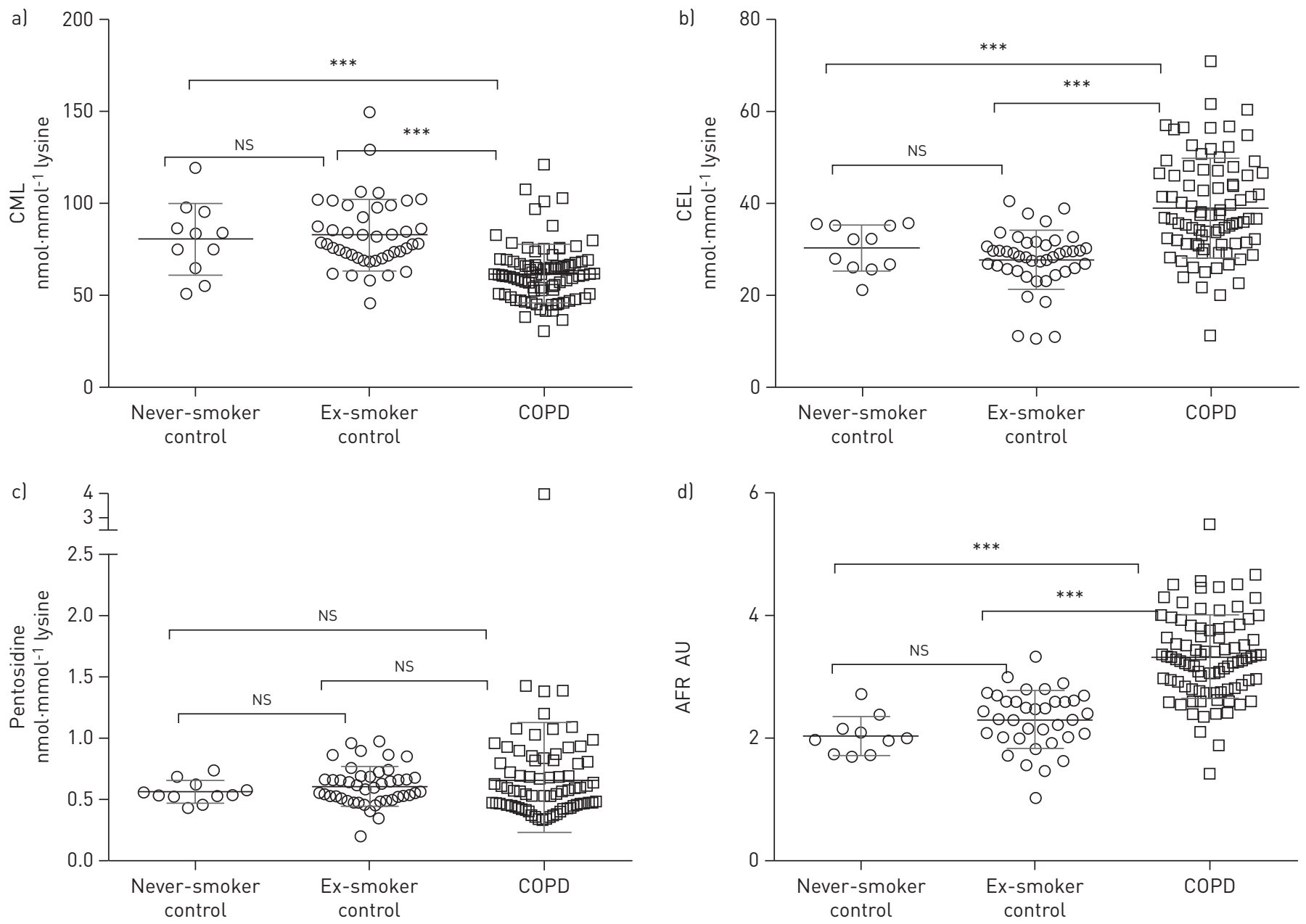

FIGURE 1 Plasma levels of a) $\mathrm{N}^{\varepsilon}$-(carboxymethyl)lysine (CML), b) $\mathrm{N}^{\varepsilon}$-(carboxyethyl)lysine (CEL) and c) pentosidine, and d) autofluorescence (AFR) in chronic obstructive pulmonary disease (COPD) patients and control subjects. NS: not significant; AU: arbitrary unit. ${ }^{* *}: \mathrm{p}<0.001$.

Comparison of characteristics between groups was performed by t-test or Chi-squared test, for continuous or categorical data, respectively. Multiple linear regression analysis was used to investigate whether disease state (COPD) and lung function were associated with increased plasma AGEs and AFR. All analyses were first adjusted for age and sex (model 1) and further for smoking (model 2) and GFR, BMI, HDL cholesterol and triglycerides (model 3). In addition, we added CRP as a marker of low-grade inflammation to the model to investigate the extent to which this variable explained (i.e. attenuated) the associations of plasma AGEs and AFR with COPD (model 4). We additionally used linear regression analysis to investigate the associations of AFR with plasma AGEs. Again, we first adjusted for age and sex (model 1), next smoking (model 2) and then GFR (model 3). All results are expressed as standardised regression coefficients to enable comparison of the strength of the associations between variables.

\section{Results}

Out of 61 healthy controls and 114 patients included, 6 controls and 26 patients were excluded from the analyses because of reflectance $<0.1$. Table 1 describes the baseline characteristics of the final study group. As expected, FEV1 was significantly lower in the COPD patients compared to the control group ( $<<0.001)$. Based on the GOLD criteria, 34 patients were categorised as GOLD stage II, 39 as GOLD stage III and 15 as GOLD stage IV. BMI was not different between controls and patients. COPD patients had smoked more pack-years compared to healthy controls. Furthermore, no differences were observed in the plasma levels of HDL cholesterol, triglycerides and glucose. Plasma creatinine and GFR levels were not significantly different. CRP was found to be increased in COPD patients compared to controls $(\mathrm{p}<0.001)$. Lastly, oxidative stress marker plasma protein carbonyls showed no difference between patients and controls. 
TABLE 2 Association of disease state with plasma advanced glycation end-products (AGEs) and autofluorescence (AFR)

\begin{tabular}{lcccc} 
Dependent variable & Model & $\boldsymbol{\beta}^{\#}$ & $\mathbf{9 5 \%} \mathbf{C l}$ & p-value \\
\hline \multirow{2}{*}{ CML } & 1 & -1.054 & $-1.348--0.761$ & $<0.001$ \\
& 2 & -1.086 & $-1.396--0.777$ & $<0.001$ \\
& 3 & -1.203 & $-1.507--0.899$ & $<0.001$ \\
CEL & 4 & -1.223 & $-1.569--0.878$ & $<0.001$ \\
& 1 & 0.982 & $0.680-1.284$ & 0.001 \\
& 2 & 1.002 & $0.683-1.321$ & 0.001 \\
In(pentosidine) & 3 & 0.915 & $0.588-1.241$ & 0.001 \\
& 4 & 0.921 & $0.551-1.292$ & 0.001 \\
& 1 & 0.067 & $-0.268-0.402$ & 0.693 \\
AFR & 2 & 0.046 & $-0.308-0.399$ & 0.799 \\
& 3 & -0.042 & $-0.386-0.301$ & 0.808 \\
& 4 & -0.075 & $-0.465-0.315$ & 0.706 \\
& 1 & 1.152 & $0.894-1.410$ & $<0.001$ \\
& 2 & 1.042 & $0.776-1.308$ & $<0.001$ \\
& 3 & 1.029 & $0.751-1.306$ & $<0.001$ \\
& 4 & 1.080 & $0.766-1.395$ & $<0.001$ \\
\hline
\end{tabular}

CML: $\mathrm{N}^{\varepsilon}$-(carboxymethyl)lysine; CEL: $\mathrm{N}^{\varepsilon}$-(carboxyethyl)lysine. ${ }^{\#}$ : differences in plasma AGEs and AFR (in SD) in individuals with versus without chronic obstructive pulmonary disease. Model 1: adjusted for age and sex; model 2: model 1 + pack-years; model 3: model 2 + glomerular filtration rate, body mass index, high-density lipoprotein cholesterol and In(triglycerides); model 4: model $3+\ln (C$-reactive protein). $n=143$.

\section{Plasma AGEs and AFR in COPD patients and controls}

Figure 1a demonstrates that (unadjusted) levels of plasma CML (COPD $61.6 \pm 15.6 \mathrm{nmol} \cdot \mathrm{mmol}^{-1}$ lysine, never-smoking controls $80.7 \pm 19.8 \mathrm{nmol} \cdot \mathrm{mmol}^{-1}$ lysine and ex-smoking controls $82.9 \pm 19.3 \mathrm{nmol} \cdot \mathrm{m}$ $\mathrm{mol}^{-1}$ lysine) were decreased in the COPD group compared to the never-/ex-smoking control group. In contrast, the plasma concentrations of CEL (fig. 1b) (COPD $39.1 \pm 10.9 \mathrm{nmol} \cdot \mathrm{mmol}^{-1}$ lysine, neversmoking controls $30.4 \pm 5.0 \mathrm{nmol} \cdot \mathrm{mmol}^{-1}$ lysine and ex-smoking controls $27.7 \pm 6.4 \mathrm{nmol} \cdot \mathrm{mmol}^{-1}$ lysine) were increased in COPD patients compared to the never-/ex-smoking control group. Plasma AGE pentosidine (fig. 1c) (COPD $0.68 \pm 0.45 \mathrm{nmol} \cdot \mathrm{mmol}^{-1}$ lysine, never-smoking controls $0.56 \pm 0.09 \mathrm{nmol} \cdot \mathrm{mmol}^{-1}$ lysine and ex-smoking controls $0.61 \pm 0.16 \mathrm{nmol} \cdot \mathrm{mmol}^{-1}$ lysine) showed no difference between the COPD group and the never-/ex-smoking control group. AFR (fig. 1c) was found to be increased in COPD compared to controls (COPD 3.33 $\pm 0.67 \mathrm{AU}$, never-smoking controls $2.05 \pm 0.31 \mathrm{AU}$ and ex-smoking controls $2.31 \pm 0.47 \mathrm{AU})$. Plasma levels of AGEs and AFR did not differ between never- and ex-smoking controls (fig. 1). Plasma levels of AGEs and AFR also did not differ between ex-smokers and currently smoking COPD patients or patients of different GOLD stages (data not shown).

\section{Associations of COPD and lung function with plasma AGEs and AFR}

Table 2 shows that, after adjustment for age, sex and pack-years (model 2), COPD was associated with a lower plasma level of CML $(\beta=-1.086,95 \%$ CI $-1.396--0.777)$, higher plasma levels of CEL $(\beta=1.002,95 \%$ CI $0.683-1.321)$ and higher AFR $(\beta=1.042,95 \%$ CI 0.776-1.308) $(\mathrm{p}<0.001)$. However, this was not the case with pentosidine $(\beta=0.046,95 \%$ CI $-0.308-0.399)$. Additional adjustment for other possible confounders (i.e. GFR, BMI, HDL cholesterol and triglycerides) did not significantly change the associations of COPD with plasma CML, CEL and AFR, which remained significant (model 3). Furthermore, in model 4 we evaluated the effect of CRP as a marker of low-grade systemic inflammation on the associations of plasma AGEs and AFR with disease state. However, we did not observe any effect on the associations.

Secondly, the associations of lung function (FEV1 \% pred) with AFR and plasma AGE levels were evaluated by regression analysis in total group. Plasma CML $(\beta=0.518,95 \%$ CI $0.352-0.685)$ was a positive determinant of lung function, and CEL $(\beta=-0.427,95 \%$ CI $-0.598--0.256)$ and AFR $(\beta=-0.402,95 \%$ CI $-0.556-0.248)$ were found to be negative determinants of lung function, even after adjusting for age, sex and pack-years $(\mathrm{p}<0.001)$ (table 3 , model 3). Additional adjustment for other confounders did not affect the association. Furthermore, when analysis was restricted to patients alone; the association of lung functions with AGEs and AFR were no longer significant (online supplementary table S1). In addition, correlation analyses were performed for AFR and AGEs with other disease makers such as diffusing capacity 
TABLE 3 Association of plasma advanced glycation end-products (AGEs) and autofluorescence (AFR) with forced expiratory volume in $1 \mathrm{~s}$ (FEV1) \% predicted

\begin{tabular}{|c|c|c|c|c|}
\hline & Model & $\beta^{\#}$ & $95 \% \mathrm{Cl}$ & p-value \\
\hline \multirow[t]{4}{*}{ CML } & 1 & 0.406 & $0.256-0.556$ & $<0.001$ \\
\hline & 2 & 0.405 & $0.249-0.562$ & $<0.001$ \\
\hline & 3 & 0.518 & $0.352-0.685$ & $<0.001$ \\
\hline & 4 & 0.508 & $0.316-0.701$ & $<0.001$ \\
\hline \multirow[t]{4}{*}{ CEL } & 1 & -0.462 & $-0.608--0.316$ & $<0.001$ \\
\hline & 2 & -0.464 & $-0.617--0.312$ & $<0.001$ \\
\hline & 3 & -0.427 & $-0.598--0.256$ & $<0.001$ \\
\hline & 4 & -0.426 & $-0.624--0.228$ & $<0.001$ \\
\hline \multirow[t]{4}{*}{ In(pentosidine) } & 1 & 0.022 & $-0.139-0.183$ & 0.790 \\
\hline & 2 & 0.035 & $-0.133-0.203$ & 0.679 \\
\hline & 3 & 0.087 & $-0.089-0.263$ & 0.331 \\
\hline & 4 & 0.127 & $-0.076-0.330$ & 0.218 \\
\hline \multirow[t]{4}{*}{ AFR } & 1 & -0.443 & $-0.579--0.307$ & $<0.001$ \\
\hline & 2 & -0.383 & $-0.520--0.246$ & $<0.001$ \\
\hline & 3 & -0.402 & $-0.556--0.248$ & $<0.001$ \\
\hline & 4 & -0.400 & $-0.578--0.222$ & $<0.001$ \\
\hline
\end{tabular}

CML: $\mathrm{N}^{\varepsilon}$-(carboxymethyl)lysine; CEL: $\mathrm{N}^{\varepsilon}$-(carboxyethyl)lysine. ${ }^{\#}$ : increase (in SD) in FEV1 \% predicted per SD increase in plasma AGEs or AFR. Model 1: adjusted for age and sex; model 2: model 1 + pack-years; model 3: model 2 + glomerular filtration rate, body mass index, high-density lipoprotein cholesterol and In(triglycerides); model 4: model $3+\ln ($ C-reactive protein). $n=143$.

of the lung for carbon monoxide (DLCO), BODE (BMI, airflow obstruction, dyspnoea, exercise capacity) and Charlson scores, but no significant correlations were observed (online supplementary table S2).

\section{Associations of plasma AGEs with AFR}

Lastly, the association between the three different plasma AGEs and AFR was evaluated. After adjustment for age, sex and pack-years, plasma CML $(\beta=-0.320$ SD, 95\% CI $-0.502--0.138 ; p=0.000)$ and CEL $(\beta=0.238$ SD, 95\% CI $0.052-0.424 ; p=0.013)$, but not pentosidine $(\beta=0.046 \mathrm{SD}, 95 \%$ CI $-0.140-0.233$; $\mathrm{p}=0.624)$, showed the association. After additional adjustment for GFR plasma, CML and CEL remained the same (table 4, model 3).

\section{Additional analyses}

Since steroids are known to have side-effects on skin [23], we compared AFR in patients taking or not taking oral steroids; this was found not to be significantly different $(3.26 \pm 0.64$ and $3.34 \pm 0.68 \mathrm{AU}$, respectively; $\mathrm{p}=0.650)$. A similar comparison was performed for plasma AGE levels, but here also no significant difference was found due to oral steroid use. Surprisingly, patients who were on combination

\begin{tabular}{|c|c|c|c|c|}
\hline & Model & $\beta^{\#}$ & $95 \% \mathrm{Cl}$ & p-value \\
\hline \multirow[t]{3}{*}{ CML } & 1 & -0.324 & $-0.493--0.154$ & $<0.001$ \\
\hline & 2 & -0.320 & $-0.502--0.138$ & 0.001 \\
\hline & 3 & -0.316 & $-0.499--0.134$ & 0.001 \\
\hline \multirow[t]{3}{*}{ CEL } & 1 & 0.254 & $0.080-0.428$ & 0.004 \\
\hline & 2 & 0.238 & $0.052-0.424$ & 0.013 \\
\hline & 3 & 0.234 & $0.048-0.421$ & 0.014 \\
\hline \multirow[t]{3}{*}{ In(pentosidine) } & 1 & 0.056 & $-0.118-0.230$ & 0.527 \\
\hline & 2 & 0.046 & $-0.140-0.233$ & 0.624 \\
\hline & 3 & 0.057 & $-0.127-0.242$ & 0.539 \\
\hline
\end{tabular}

CML: $\mathrm{N}^{\varepsilon}$-(carboxymethyl(lysine; CEL: $\mathrm{N}^{\varepsilon}$-(carboxyethylllysine. ${ }^{\#}$ : increase (in SD) in AFR per SD increase in plasma AGEs. Model 1: adjusted for age and sex; model 2: model 1 + pack-years; model 3: model $2+$ glomerular filtration rate. $\mathrm{n}=143$. 
therapy of LABA and inhaled corticosteroids showed higher AFR than those who were not $(3.5 \pm 0.65$ and $3.2 \pm 0.68$ AU, respectively; $p=0.042$ ). We did not observe any difference in plasma AGEs or AFR between individuals who were using statins versus those who were not.

\section{Discussion}

The present study is the first to analyse different plasma AGEs and AFR in patients with COPD. While unadjusted plasma levels of CML were decreased, CEL and AFR were found to be increased in COPD patients compared to never- and ex-smoking controls. Importantly, after adjusting for potential confounders, CML was shown to be a negative determinant of disease state, and CEL and AFR positive determinants of disease state. Lung function measured by FEV1 \% pred showed an association with CML, CEL and AFR in the total group, but not when the analysis was restricted to the patient group.

Among many different AGEs, we investigated three protein-bound AGEs in plasma, i.e. CML, CEL and pentosidine. It is known that the three AGEs that we measured in our study have distinct functionalities; pentosidine as a major cross-linking AGE, CML as a major ligand for the AGE receptor, and, importantly, CEL as a putative marker for intracellular glycation. Interestingly, the precursor molecule for CEL [24], methylglyoxal, is a highly reactive compound causing cell death [25].

CML was decreased in COPD patients compared to the never- and ex-smoking controls. However, previously, we and others showed that the plasma CML was not different in COPD patients compared to controls. In our former study, as well as in another publication, CML levels were determined by ELISA and uncorrected for lysine content $[26,27]$ as opposed to the measurement by mass spectrometry employed here. Interestingly, change in the direction of plasma protein-bound CML levels are in line with plasma concentration of the soluble receptor for AGE in COPD. In contrast, a recent pilot study showed an increase in the levels of CML, measured by competitive ELISA, in the epithelial lining fluid of small airways in COPD [15]. Importantly, this study found a positive association of CML with the oxidative stress marker 8-isoprostane as well as interleukin-8, and a negative association with FEV1. However, this study did not measure the CML concentrations in circulation. Therefore, it might be that a change of CML in the lung tissue is not reflected by altered plasma levels.

This is the first report on the AGE CEL in COPD. Elevated circulating levels of protein-bound CEL were found in COPD compared to never- and ex-smoking controls. Primarily, it would be interesting to test whether increased plasma CEL levels as determined here could arise from elevated pulmonary levels or have a different source of origin. Secondly, extracellular toxicity/intracellular glycation via methylglyoxal/CEL might be a molecular mechanism in COPD pathogenesis which needs to be further explored. In the present study we were unable to measure methylglyoxal in the circulation. The fluorescent AGE, pentosidine, which requires oxygen for its formation [28], was not found to be altered in the plasma of COPD patients compared to controls.

Studies have shown that AGEs are formed from glucose [24, 29, 30] and lipids [31, 32] by the slow classical pathway. It is important to highlight that diabetic patients were excluded from our study population, which makes it likely that the alterations in AGE levels in COPD are derived from other pathways rather than from glucose. Furthermore, inflammation and oxidative stress [33], even in the absence of increased glycaemia $[34,35]$, may lead to the formation of AGEs in a short time course, i.e. within a few hours [36]. However, we currently found that the positive association of COPD with plasma CEL and AFR, and the negative association of CML, were independent of CRP. To fully rule out a role for inflammation in the formation of AGEs in COPD, it may be necessary to measure a panel of plasma inflammatory markers [37]. Moreover, the association of COPD with plasma levels of CEL and CML was also independent of BMI, blood lipids and GFR. Neither inhaled or oral steroid use, nor smoking status, had effects on plasma AGEs. From our study it is clear that increases in CEL and decreases in CML levels in the circulation are due to the disease state, but further investigation is needed to elaborate the exact processes underlying these differences in COPD.

Regression analysis showed that plasma CML was independently negatively associated with disease state but CEL was independently, positively associated with disease state. Interestingly, CML and CEL were found to be associated with lung function only in the total group and there were no observed correlations of plasma AGEs with other parameters of disease such as DLCO or BODE or Charlson comorbidity scores, implying that the cumulative factor from the disease state is a driving force for differences in AGEs, rather than FEV1 alone. Our results show that AGEs may not be directly related to the degree of lung function impairment in COPD.

Other studies have shown that AGEs are increased in diseases such as atherosclerosis [38], osteoporosis [39] and diabetes [40], which are common comorbidities in patients with COPD. The cardiovascular complications in diabetes are postulated to be due to the high levels of AGEs in the circulation [40]. In addition, CML has been found on the inner walls of arteries in patients suffering from an acute myocardial 
infarction in the absence of diabetes [41]. Importantly, in the present study diabetics were excluded and other comorbidities were not frequent enough to investigate their contribution to the increased AGE levels in COPD. Therefore, prospective large longitudinal studies are needed to fully elucidate the potential mediating factors, including comorbidities, involved in COPD-induced changes in plasma and skin AGEs, and vice versa.

From the present data, we cannot elucidate whether the increase in AFR is due to a direct effect of smoking on skin collagens, whether it is a systemic consequence of the lung pathology or whether it is an effect of medication use. There is indeed evidence that smoking increases AFR [12, 42]. KoETSIER et al. [12], for instance, showed that AFR was increased in current smokers compared to non-smokers after correcting for age, but their study group was devoid of ex-smokers. In the present study, we did not find a difference in the AFR between current smoking patients and ex-smoking patients (data not shown). Furthermore, adjusting for pack-years smoked did not affect the relationship between AFR and disease status. With respect to the latter possibility, NOORDZI et al. [43] reported that vasodilatation and vasoconstriction caused a respective decrease and increase in AFR. It is known that corticosteroids cause vasoconstriction and most COPD patients are taking either a low dosage of oral steroids or a medium-to-high dosage of inhaled steroids. However, we did not find an effect of oral steroid use on AFR. Combination therapy of LABA and inhaled corticosteroids was found to be associated with an increase in AFR, whereas no effect on plasma AGEs was observed. The individual medications did not affect AFR and a possible mechanism behind the combined treatment remains to be investigated.

The study which validated the AGE reader showed a correlation between AFR and collagen-linked AGEs from skin, but the authors did not investigate the association between plasma AGEs and the AFR [44]. From this it is not clear whether the AGEs are formed locally in the skin or whether they accumulate from the circulation. In the present study we thus evaluated the association between AFR and AGEs in circulation and we showed that the CEL and CML were associated with AFR. Surprisingly, we did not find an association of the fluorescent AGE pentosidine with the AFR.

In this study population, from the $114 \mathrm{COPD}$ patients and 61 controls, we eliminated 22 patients and six controls from further analyses because the AFR reflection value was $<0.1$. During the validation of the AGE reader the major reason for a reflection value $<0.1$ was skin colour, with skin prototypes (SPTs) V and VI causing reflection $<0.1$ [20]. However, in this population, SPT II-IV showed a lower reflection value. Importantly, the age reader that we used was an older version, which cannot consider reflection of $<0.1$. However, the more recent versions recalculate AFR with reflection $<0.1$.

In conclusion, it is clear from our study that specific AGEs in the circulation and AFR are increased in COPD patients. Importantly, CEL and AFR were negatively associated with disease state and CML was positively associated with it. Plasma CML, CEL and AFR showed an association with FEV1, but only in the total group. It is important to further investigate the adverse effect of AGEs, and in particular of CEL, on the respiratory system and specifically the lung.

\section{Acknowledgements}

This work was performed at CIRO+ (The Centre of Expertise for Chronic Organ Failure, Horn, the Netherlands). We thank the COPD patients and the healthy subjects who volunteered to participate in the study. Moreover, we are grateful to T. Hofstra, A. Suntjens, M. Akkermans, L. Op’t Veld, K. Stakenborg, J. Peeters, M. Cuijpers, A. van de Kruijs, I. Timmermans, M. Groenen and R. van Kessel (CIRO+), for planning and performing all the tests.

\section{References}

Barnes PJ, Celli BR. Systemic manifestations and comorbidities of COPD. Eur Respir J 2009; 33: 1165-1185. Singh R, Barden A, Mori T, et al. Advanced glycation end-products: a review. Diabetologia 2001; 44: 129-146. Schleicher E, Friess U. Oxidative stress, AGE, and atherosclerosis. Kidney Int Suppl 2007; 106: S17-S26. Kokkola R, Andersson A, Mullins G, et al. RAGE is the major receptor for the proinflammatory activity of HMGB1 in rodent macrophages. Scand J Immunol 2005; 61: 1-9.

5 Sparvero LJ, Asafu-Adjei D, Kang R, et al. RAGE (Receptor for Advanced Glycation Endproducts), RAGE ligands, and their role in cancer and inflammation. J Transl Med 2009; 7: 17.

6 Bierhaus A, Hofmann MA, Ziegler R, et al. AGEs and their interaction with AGE-receptors in vascular disease and diabetes mellitus. I. The AGE concept. Cardiovasc Res 1998; 37: 586-600.

Monnier VM. Nonenzymatic glycosylation, the Maillard reaction and the aging process. J Gerontol 1990; 45: B105-B111.

8 Monnier VM, Kohn RR, Cerami A. Accelerated age-related browning of human collagen in diabetes mellitus. Proc Natl Acad Sci USA 1984; 81: 583-587.

9 Ahmed MU, Brinkmann Frye E, Degenhardt TP, et al. N-E-(carboxyethyl)lysine, a product of the chemical modification of proteins by methylglyoxal, increases with age in human lens proteins. Biochem J 1997; 324: 565-570.

10 Dyer DG, Dunn JA, Thorpe SR, et al. Accumulation of Maillard reaction products in skin collagen in diabetes and aging. J Clin Invest 1993; 91: 2463-2469. 
11 Mulder DJ, Water TV, Lutgers HL, et al. Skin autofluorescence, a novel marker for glycemic and oxidative stressderived advanced glycation endproducts: an overview of current clinical studies, evidence, and limitations. Diabetes Technol Ther 2006; 8: 523-535.

12 Koetsier M, Lutgers HL, de Jonge C, et al. Reference values of skin autofluorescence. Diabetes Technol Ther 2010; 12: 399-403.

13 Januszewski AS, Sachithanandan N, Karschimkus C, et al. Non-invasive measures of tissue autofluorescence are increased in type 1 diabetes complications and correlate with a non-invasive measure of vascular dysfunction. Diabet Med 2012; 29: 726-733.

14 Meerwaldt R, Lutgers HL, Links TP, et al. Skin autofluorescence is a strong predictor of cardiac mortality in diabetes. Diabetes Care 2007; 30: 107-112.

15 Kanazawa H, Kodama T, Asai K, et al. Increased levels of $\mathrm{N} \varepsilon$-(carboxymethyl)lysine in epithelial lining fluid from peripheral airways in patients with chronic obstructive pulmonary disease: a pilot study. Clin Sci (Lond) 2010; 119: $143-149$.

16 Rabe KF, Hurd S, Anzueto A, et al. Global strategy for the diagnosis, management, and prevention of chronic obstructive pulmonary disease: GOLD executive summary. Am J Respir Crit Care Med 2007; 176: 532-555.

17 Teerlink T, Barto R, Ten Brink HJ, et al. Measurement of Ne-(carboxymethyl)lysine and Ne-(carboxyethyl)lysine in human plasma protein by stable-isotope-dilution tandem mass spectrometry. Clin Chem 2004; 50: 1222-1228.

18 Scheijen JL, van de Waarenburg MP, Stehouwer CD, et al. Measurement of pentosidine in human plasma protein by a single-column high-performance liquid chromatography method with fluorescence detection. J Chromatogr $B$ Analyt Technol Biomed Life Sci 2009; 877: 610-614.

19 Levine RL, Garland D, Oliver CN, et al. Determination of carbonyl content in oxidatively modified proteins. Methods Enzymol 1990; 186: 464-478.

20 Cockcroft DW, Gault MH. Prediction of creatinine clearance from serum creatinine. Nephron 1976; 16: 31-41.

21 Mulder DJ, Water TV, Lutgers HL, et al. Skin autofluorescence, a novel marker for glycemic and oxidative stressderived advanced glycation endproducts: an overview of current clinical studies, evidence, and limitations. Diabetes Technol Ther 2006; 8: 523-535.

22 Meerwaldt R, Graaff R, Oomen PH, et al. Simple non-invasive assessment of advanced glycation endproduct accumulation. Diabetologia 2004; 47: 1324-1330.

23 Nordlund JJ, Ackles AE, Lerner AB. The effects of ultraviolet light and certain drugs on La-bearing Langerhans cells in murine epidermis. Cell Immunol 1981; 60: 50-63.

24 Thornalley PJ, Langborg A, Minhas HS. Formation of glyoxal, methylglyoxal and 3-deoxyglucosone in the glycation of proteins by glucose. Biochem J 1999; 344: 109-116.

25 Ispolnov K, Gomes RA, Silva MS, et al. Extracellular methylglyoxal toxicity in Saccharomyces cerevisiae: role of glucose and phosphate ions. J Appl Microbiol 2008; 104: 1092-1102.

26 Gopal P, Rutten EP, Dentener MA, et al. Decreased plasma sRAGE levels in COPD: influence of oxygen therapy. Eur J Clin Invest 2012; 42: 807-814.

27 Miniati M, Monti S, Basta G, et al. Soluble receptor for advanced glycation end products in COPD: relationship with emphysema and chronic cor pulmonale: a case-control study. Respir Res 2011; 12: 37.

28 Baynes JW, Thorpe SR. Glycoxidation and lipoxidation in atherogenesis. Free Radic Biol Med 2000; 28: 1708-1716.

29 Thornalley PJ, Jahan I, Ng R. Suppression of the accumulation of triosephosphates and increased formation of methylglyoxal in human red blood cells during hyperglycaemia by thiamine in vitro. J Biochem 2001; 129: 543-549.

30 Dyer DG, Blackledge JA, Thorpe SR, et al. Formation of pentosidine during nonenzymatic browning of proteins by glucose. Identification of glucose and other carbohydrates as possible precursors of pentosidine in vivo. J Biol Chem 1991; 266: 11654-11660.

31 Fu MX, Requena JR, Jenkins AJ, et al. The advanced glycation end product, Ne-(carboxymethyl)lysine, is a product of both lipid peroxidation and glycoxidation reactions. J Biol Chem 1996; 271: 9982-9986.

32 Miyata T, Inagi R, Asahi K, et al. Generation of protein carbonyls by glycoxidation and lipoxidation reactions with autoxidation products of ascorbic acid and polyunsaturated fatty acids. FEBS Lett 1998; 437: 24-28.

33 Wolff SP, Dean RT. Glucose autoxidation and protein modification. The potential role of "autoxidative glycosylation" in diabetes. Biochem J 1987; 245: 243-250.

34 Baynes JW, Thorpe SR. Role of oxidative stress in diabetic complications: a new perspective on an old paradigm. Diabetes 1999; 48: 1-9.

35 Baynes JW. Role of oxidative stress in development of complications in diabetes. Diabetes 1991; 40: 405-412.

36 Yamagishi S. Advanced glycation end products and receptor-oxidative stress system in diabetic vascular complications. Ther Apher Dial 2009; 13: 534-539.

37 Agustí A, Edwards LD, Rennard SI, et al. Persistent systemic inflammation is associated with poor clinical outcomes in COPD: a novel phenotype. PLoS One 2012; 7: e37483.

38 Wautier JL, Schmidt AM. Protein glycation: a firm link to endothelial cell dysfunction. Circ Res 2004; 95: 233-238.

39 Yamagishi S, Nakamura K, Inoue $\mathrm{H}$, et al. Possible participation of advanced glycation end products in the pathogenesis of colorectal cancer in diabetic patients. Med Hypotheses 2005; 64: 1208-1210.

40 Nin JW, Jorsal A, Ferreira I, et al. Higher plasma levels of advanced glycation end products are associated with incident cardiovascular disease and all-cause mortality in type 1 diabetes: a 12-year follow-up study. Diabetes Care 2011; 34: 442-447.

41 Baidoshvili A, Krijnen PA, Kupreishvili K, et al. $\mathrm{N}^{\varepsilon}$-(carboxymethyl)lysine depositions in intramyocardial blood vessels in human and rat acute myocardial infarction: a predictor or reflection of infarction? Arterioscler Thromb Vasc Biol 2006; 26: 2497-2503.

42 Lutgers HL, Graaff R, Links TP, et al. Skin autofluorescence as a noninvasive marker of vascular damage in patients with type 2 diabetes. Diabetes Care 2006; 29: 2654-2659.

43 Noordzij MJ, Lefrandt JD, Graaff R, et al. Dermal factors influencing measurement of skin autofluorescence. Diabetes Technol Ther 2011; 13: 165-170.

44 Meerwaldt R, Hartog JW, Graaff R, et al. Skin autofluorescence, a measure of cumulative metabolic stress and advanced glycation end products, predicts mortality in hemodialysis patients. J Am Soc Nephrol 2005; 16: 3687-3693. 